\title{
A concepção de hegemonia no pensamento de Antonio Gramsci
}

\section{La concezione dell'egemonia nel pensiero di Antonio Gramsci}

\author{
The conception of hegemony in Antonio Gramsci's thought
}

\author{
Karine Martins Sobral \\ Universidade Federal do Maranbão (UFMA) \\ Ellen Cristine dos Santos Ribeiro \\ Universidade Estadual do Ceará (UECE)
}

\begin{abstract}
Resumo: O estudo prima por evidenciar as formulações de Gramsci sobre a categoria hegemonia, entendendo-a como um elemento-chave para a compreensão de seu complexo universo teórico. A relevância do esforço em apreender os conceitos gramscianos reside na tentativa de captar elementos produzidos por uma teoria que, além do rigor teóricocientífico balizado pela filosofia da práxis, é capaz de fornecer as condições de articulação entre os processos atuais de dominação e o momento de grande ofensiva ideológica conservadora. A pesquisa, de natureza teórico-bibliográfica, apontou a evolução do tema ao longo da produção carcerária de Gramsci, afastando-o de leituras reducionistas.
\end{abstract}

Palavras-chave: Gramsci; Hegemonia; Educação.

Riassunto: Lo studio cerca di evidenziare le formulazioni di Gramsci sulla categoria dell'egemonia, comprendendola come un elemento-chiave per comprendere il suo complesso universo teorico. L'importanza dello sforzo di comprendere i concetti gramsciani sta nel tentativo di catturare elementi prodotti da una teoria che, oltre al rigore teorico e scientifico guidato dalla filosofia della praxis, è in grado di fornire le condizioni per articolare gli attuali processi di dominio e momento di grande offensiva ideologica conservatrice. Il lavoro, di natura teorico-bibliografica, ha sottolineato l'evoluzione del tema durante la produzione di Gramsci, allontanandolo dalle letture riduzioniste.

Parole-chiave: Egemonia; Gramsci; Educazione. 
Abstract: The study excels at highlighting Gramsci's formulations about the hegemony category, understanding it as a key element to comprehend his complex theoretical universe. The relevance of the effort to apprehend grammatical concepts lies in the attempt to capture the elements caused by a theory that, in addition to the theoretical-scientific rigor guided by the philosophy of praxis, is capable of providing the conditions for articulation between the current processes of domination and the moment of great conservative ideological offensive. The research, of a theoretical-bibliographic nature, pointed out the evolution of the theme throughout Gramsci's prison production, moving him away from reductionist readings.

Keywords: Gramsci; Hegemony; Education.

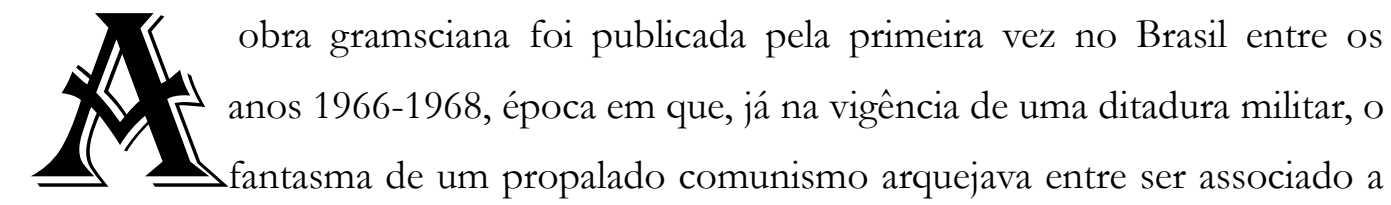
regimes totalitários, violentos, e o medo disseminado entre a população por diversas instituições. Apesar da mobilização de vários intelectuais ligados ao Partido Comunista Brasileiro (PCB) na edição e circulação dos escritos de Antonio Gramsci, a empreitada teve pouca repercussão.

Nos anos 1980, momento em que sua teoria já permeava discussões e formulações estratégicas no interior dos partidos de esquerda acerca de uma frente política pela democracia, Gramsci foi utilizado em maior escala pelo Partido dos Trabalhadores (PT), e, no entender de Del Roio (2019), não representou o fomento de uma estratégia política que fizesse oposição ao reformismo preeminente nessa organização. Ao contrário, significou o deslocamento de um grupo considerável de intelectuais para a perspectiva liberaldemocrata, o que, por seu turno, agregou aos acirrados debates acerca do conceito de hegemonia o rescaldo das proposições de autores como Jürgen Habermas e Norberto Bobbio. $^{1}$

No campo da educação e do serviço social, sobretudo nas pesquisas relacionadas às políticas públicas, permanece até os dias atuais como importante referencial, alvo de diversas apropriações indevidas, forjadas para justificar ações assistencialistas do Estado que se prestam à preservação da ordem social capitalista.

\footnotetext{
1 Jürgen Habermas (1929) foi um filósofo e sociólogo alemão. Assistente de Theodor Adorno e membro da Escola de Frankfurt, cuja obra sofreu influência do pensamento pós-estruturalista. Norberto Bobbio (19092004), filósofo político italiano, defensor da democracia social-liberal.
} 
A fase atual, marcada pela crise orgânica ${ }^{2}$ do capitalismo, presencia a ascensão de partidos e organizações de extrema-direita e a repressão das massas populares, o que, necessariamente, nos remete à concepção gramsciana de hegemonia, indispensável à interpretação de tais eventos e dos fundamentos do capitalismo. Anita Schlesener, ao prefaciar Del Roio (2018, p. 7), relembra que o país, atravessando um momento de capitalismo imperialista, "com uma história política e cultural de raiz conservadora, com breves períodos de frágil democracia burguesa, revela ao mundo suas contradições históricas".

Conceituar hegemonia constitui-se como um ponto-chave para a compreensão da obra gramsciana em sua totalidade, por se tratar de uma categoria que perpassa todas as outras e que contém em si importantes facetas do complexo universo construído ao longo da produção de Gramsci. Com efeito, todos os conceitos primordiais que alicerçam a obra de Gramsci (subalternidade, reforma intelectual e moral, revolução passiva, educação e autoeducação das massas, jacobinismo, para citar alguns) remetem uns aos outros, numa articulação laboriosa, indispensável à compreensão do conjunto de seu pensamento.

Dias (1991) alerta para o tratamento correto de tal categoria na perspectiva do revolucionário sardo: compreendendo que a capacidade de construção de uma hegemonia decorre da possibilidade de que uma classe fundamental, dominante ou subalterna, elabore sua visão de mundo; que essa classe seja capaz de estruturar o campo de lutas de modo a determinar frentes de intervenção e articular alianças. Ressalta, ainda, o exame da questão da hegemonia como reforma intelectual e moral, isto é, a partir da construção de uma concepção de mundo, a qual precisa necessariamente estar atrelada a um programa de transformação radical da economia.

Gramsci entendia a construção de uma nova hegemonia como uma unidade entre teoria e ação. Uma teoria capaz de traduzir, em realidade, a ação do proletariado para a edificação de novas relações sociais de produção. Assim como uma nova superestrutura, com novos aparelhos de hegemonia que difundissem uma concepção de mundo unitária, uma sociedade civil restaurada que, em conexão orgânica com a estrutura, se torne capaz de destruir o Estado em sentido restrito. Seria um processo de reabsorção da sociedade política pela sociedade civil.

\footnotetext{
${ }^{2}$ De acordo com o revolucionário sardo, “[...] o conteúdo [da crise orgânica] é a crise de hegemonia da classe dirigente, que ocorre ou porque a classe dirigente fracassou em algum grande empreendimento político para o qual pediu ou impôs pela força o consenso das grandes massas (como a guerra), ou porque amplas massas (sobretudo de camponeses e de pequenos burgueses intelectuais) passaram subitamente da passividade política para uma certa atividade e apresentam reivindicações que, em seu conjunto desorganizado, constituem uma 'revolução'. Fala-se de 'crise de autoridade': e isso é precisamente a crise de hegemonia, ou crise do Estado em seu conjunto” (GRAMSCI, 2016, v. 3, C. 13, \23, p. 60).
} 


\section{Frente única e hegemonia}

No intuito de perscrutar uma das principais referências teóricas do pensamento gramsciano, faz-se urgente recuperar, ainda que de forma breve, os pressupostos leninistas que influenciaram a teoria e a ação política de Gramsci. A imersão no conceito de hegemonia aqui empreendida possibilita demonstrar a íntima relação entre os dois marxistas, respeitando, contudo, as vivências e as experiências políticas distintas.

Os efeitos produzidos pela articulação entre Lenin e o bolchevismo foram determinantes para a organização teórico-prática do pensamento gramsciano, sobretudo a partir de 1923, quando, ao encaminhar ao Partito Comunista d'Italia (PCd'I) a síntese melhor elaborada de sua teoria, alcança um lugar de protagonismo dentro do partido, ao passo que expõe sua estratégia de luta revolucionária no contexto da particularidade italiana. "Nesse movimento do pensamento é que Gramsci envereda para o caudal da refundação comunista, vindo a ser exatamente o elemento mais destacado de seu aprofundamento e desenvolvimento teórico-político" (DEL ROIO, 2019, p. 31).

O que testemunha o rigor teórico marxiano na obra gramsciana é o vínculo permanente entre o processo de produção industrial e as articulações políticas numa perspectiva operário-socialista. O marco de sua nova síntese teórica, amadurecida em patamares superiores, é o modelo da frente única.

De Lenin é a apreensão da necessidade de traduzir a particularidade da Revolução Russa na particularidade da revolução italiana, num estranho movimento dialético que passa do universal para as diferentes particularidades. Daí a necessidade de pensar a aliança operário-camponesa. Mas a trajetória de Gramsci, paradoxalmente, aponta o caminho para Marx. Esse caminho mostrou-se facilitado pela permanência em sua concepção teórica da centralidade da fábrica e do mundo operário na teoria e na prática, trazido por Sorel, Korsch e Rosa (DEL ROIO, 2019, p. 31).

O próprio Gramsci admite, em alguns já conhecidos trechos de sua obra, a matriz leninista do conceito de hegemonia: "Disto decorre que o princípio teórico-prático da hegemonia possui também um alcance gnosiológico; e, portanto, é nesse campo que se deve buscar a contribuição teórica máxima de Ilitch à filosofia da práxis” (GRAMSCI, 2006, v. 1, C. 10 , \ 12, p. 320). Em outra passagem, afirma: “[...] assinalei a importância filosófica do conceito e da realidade da hegemonia, devido a Ilitch" (GRAMSCI, 2006, v. 1, C. $7, \int 33$, p. 242). Temos, assim, a comprovação de que o pensador sardo não pretendia criar algo novo, mas apurar o conceito de hegemonia cunhado por Lenin, ponto fundamental de sua teorização.

[...] o problema essencial para ele [Lenin] é a derrubada, pela violência, do aparelho de Estado: a sociedade política é o objetivo e, para atingi-lo, uma prévia hegemonia política é necessária: hegemonia política porque a sociedade política é mais importante, em suas preocupações estratégicas, do que a civil [...] 
Gramsci, ao contrário, situa o terreno essencial da luta contra a classe dirigente na sociedade civil: o grupo que a controla é hegemônico e a conquista da sociedade política coroa essa hegemonia, estendendo-a ao conjunto do Estado (sociedade civil mais sociedade política) (PORTELLI, 1977, p. 65).

Há, no termo hegemonia, um caráter militar inegável. A ressalva é feita por Gruppi (1978) ao retomar a forma como os gregos viam nesse vocábulo um equivalente para liderança, comando. Lenin delimitou hegemonia como direção política, a partir da organização da classe trabalhadora, tendo em vista a implementação de uma nova ordem social. Conquistar a hegemonia era, pois, um elemento central a ser resolvido política e teoricamente. Pode-se elaborar, portanto, que hegemonia, no âmbito gramsciano, é a preponderância da sociedade civil sobre a sociedade política.

Gramsci começa a desenvolver seu conceito de hegemonia como desdobramento da reflexão realizada sobre a fórmula teórico-política da frente única, ainda que a partir das contribuições de Georg Sorel, Rosa Luxemburgo e, sobretudo, Lenin. Assim como Marx estudou em profundidade o capitalismo para pensar uma sociedade pautada pelo fim da exploração do homem pelo homem, Gramsci analisou diferentes formas de hegemonia burguesa a fim de encontrar o percurso a ser trilhado para a construção de uma hegemonia das classes subalternas na Itália e no mundo. Segundo Del Roio (2019), essa elaboração começa a ganhar corpo na obra gramsciana a partir do debate empreendido por Lenin em torno da tática de frente única e de suas ponderações sobre o período posterior à derrota da revolução socialista internacional, momento em que tal política passou a ser defendida no âmbito da terceira Internacional Comunista e da Nova Economia Política existente na União Soviética.

Gruppi (1978) identifica, no debate da concepção de Estado em Gramsci, dois importantes aspectos da acepção leniniana: o primeiro constitui-se como uma das principais divergências com os anarquistas, que é a necessidade de tomar o Estado e implementar a ditadura revolucionária do proletariado, o que pode ser utilizado como sinônimo de hegemonia, embora resguarde algumas diferenças; o segundo relaciona-se com a imposição da construção de um intelectual coletivo, capaz de dirigir as classes subalternas e seus aliados na tomada do poder estatal, central na concepção de partido formulada por Gramsci.

A frente única e a nova hegemonia em construção demandavam a elaboração de uma nova cultura, de modo que a primeira, ao desenvolver uma atividade predominantemente política, ultrapassava essa dimensão, dado o seu caráter transformador. Em seu último escrito político, intitulado A questão meridional, o próprio Gramsci (2004, p. 408) afirma sobre a tática da frente única: 


\begin{abstract}
Os comunistas turinenses haviam formulado de modo concreto a questão da "hegemonia do proletariado", ou seja, da base social da ditadura proletária e do Estado operário. $\mathrm{O}$ proletariado pode se tornar classe dirigente e dominante na medida em que consegue criar um sistema de alianças de classe que lhe permita mobilizar contra o capitalismo e o Estado burguês a maioria da população trabalhadora.
\end{abstract}

Gruppi (1978) define hegemonia em Gramsci como a capacidade de viabilizar uma base social ao Estado proletário. Nessa acepção, pode-se afirmar que a hegemonia do proletariado se realiza na sociedade civil, ao passo que a ditadura do proletariado é o aspecto estatal [no sentido restrito] assumido pela hegemonia. Contudo, também é imprescindível constituir-se como força capaz de reprimir as classes adversárias a transformação radical da forma de sociabilidade capitalista. “[...] na noção geral de Estado entram elementos que devem ser remetidos à noção de sociedade civil (no sentido, seria possível dizer, de que Estado = sociedade política + sociedade civil, isto é, hegemonia couraçada de coerção)" (GRAMSCI, 2016, v. 3, C. 6, \88, p. 248).

Gramsci (2006) entende a liberdade e a necessidade do mundo dos homens como um processo aberto à ação dos grupos de uma determinada forma de sociedade e dos indivíduos, uma vez que o homem ativo de massa, apesar de atuar na prática, não tem uma consciência teórica clara dessa ação, porquanto se trata de um conhecimento de mundo na medida em que é transformado. Além do mais,

[a] consciência de fazer parte de uma determinada força hegemônica (isto é, a consciência política) é a primeira fase de uma ulterior e progressiva autoconsciência, na qual teoria e prática finalmente se unificam. Portanto, também a unidade de teoria e prática não é um dado de fato mecânico, mas um devir histórico, que tem a sua fase elementar e primitiva no sentimento de "distinção", de "separação", de independência quase instintiva, e progride até a aquisição real e completa de uma concepção do mundo coerente e unitária. E por isso que se deve chamar a atenção para o fato de que o desenvolvimento político do conceito de hegemonia representa, para além do progresso políticoprático, um grande progresso filosófico, já que implica e supõe necessariamente uma unidade intelectual e uma ética adequada a uma concepção do real que superou o senso comum e tornou-se crítica, mesmo que dentro de limites ainda restritos (GRAMSCI, 2006, v. 1, C. 11, \12, p. 103-104).

Gramsci acreditava que somente com a elevação da cultura da classe trabalhadora seria possível formar dirigentes de um Novo Estado, o Estado Operário. A partir desse paradigma e com o objetivo de articular o conhecimento técnico-operacional dos trabalhadores ao conhecimento mais erudito das ciências naturais e da cultura humanística, a escola chega ao interior das fábricas. As principais inferências obtidas são as de que os Conselhos de Fábrica representam um esforço teórico fundamental de Gramsci para elaborar uma teoria revolucionária e se circunscrevem no centro do processo de transição para sua maturidade intelectual. 
Tal movimento representava a efervescência de trabalhadores que passaram a usufruir da capacidade de autogoverno e que, para adquirirem autonomia, precisariam demonstrar que os patrões eram totalmente dispensáveis. Durou, aproximadamente, dois anos (1919-1920) e teve como marco inicial a deflagração de uma greve geral na cidade de Turim. Com adesão de mais de 200 mil trabalhadores, configurou-se, entretanto, de forma diferente, pois, em vez de os trabalhadores faltarem ao trabalho, foram para dentro das fábricas sob o comando dos conselhos operários que lá funcionavam.

Gramsci entendia, de acordo com Del Roio (2018), que os trabalhadores, no próprio processo de trabalho, eram capazes de se educar e adquirir conhecimento técnicocientífico-humanístico para reorganizar o processo produtivo, aumentando a produção e, portanto, as comissões de fábrica, que seriam o próprio germe do Novo Estado, o Estado Operário. Era a formação de uma espécie de novo poder paralelo ao poder dominante essa ideia tinha a influência dos conselhos operários alemães, particularmente influenciados pela produção intelectual de Karl Korsh e Georg Sorel. A experiência demonstra na prática o esforço de Gramsci e seu grupo de vincular economia, política e cultura, numa demonstração de que "um dos princípios básicos dos escritos gramscianos é de que a sociedade civil e a hegemonia dizem respeito à totalidade social em processo contraditório, cujo fundamento se encontra na produção da vida material realizada por meio do trabalho do homem social” (DEL ROIO, 2018, p. 152).

Gramsci discute a racionalização e a produção do trabalho reconhecendo a importância que tiveram nos Estados Unidos e sua necessidade de mudança radical da sociedade, bem como as transformações concomitantes ocorridas no modo de vida e organização do trabalho no interior da fábrica. O intuito era compor um novo perfil de trabalhador. Na passagem que segue, as aspas grafadas no termo moralidade dão a entender que não se trata de uma questão moral, e sim política:

\footnotetext{
$\mathrm{Na}$ América, a racionalização do trabalho e o proibicionismo $^{3}$ estão indubitavelmente ligados: as investigações dos industriais sobre vida íntima dos operários, os serviços de inspeção criados por algumas empresas para controlar a "moralidade" dos operários são necessidades do novo método de trabalho (GRAMSCI, 2007, v. 4, C. 22, \11, p. 266).
}

Derrotar os grupos contrários ao proibicionismo não era uma tarefa menor, pois havia uma intrínseca relação entre este e a racionalização da produção. Não à toa, os industriais investigavam o estilo de vida de seus operários, já que um homem que gastasse suas energias psicofísicas numa noite de esbórnia, por exemplo, não estaria apto para

\footnotetext{
${ }^{3} \mathrm{O}$ termo proibicionismo refere-se à lei que coibia a fabricação e o consumo de álcool nos Estados Unidos, em 1920.
} 
produzir no dia seguinte. Por isso que "[...] a luta contra o álcool, o mais perigoso agente de destruição das forças de trabalho, torna-se função do Estado [...]" (GRAMSCI, 2007, v. 4, C. $22, \int 11$, p. 267). Daí o fato de tais iniciativas não poderem ser tomadas em sua compreensão meramente moral.

A racionalização da composição demográfica europeia se deu, naquele momento, em virtude da tentativa de os Estados europeus se beneficiarem dos avanços ocorridos na esfera da produção. Gramsci (2007) identifica que o americanismo necessita de uma “composição demográfica racional" (v. 4, C. 22, \ 2, p. 243), na qual não existam "classes numerosas sem uma função essencial no mundo produtivo" (GRAMSCI, 2007, v. 4, C. 22, $\int 1$, p. 242), como é o caso da Europa com suas classes parasitárias, que vivem de herança familiar, típicas de países antigos.

A título de exemplificação, cita o caso de Nápoles. Apesar de, à época, ser a quarta cidade industrial do país, ficando atrás apenas de Milão, Turim e Gênova, tinha uma população parasitária. Também denuncia a exploração dos produtores rurais para custear uma burguesia proprietária de terras, sustentada pelo aluguel dessas terras, ao estilo feudal. Aponta, também, a administração do Estado como fonte de parasitismo. Traça, por fim, um paralelo com a América que, apesar de não acumular a tradição histórica e cultural da Europa, apresenta uma composição demográfica livre de parasitismo e forças materiais de produção - matéria-prima, máquinas, técnicas - que permitiram "uma base sadia para a indústria” (GRAMSCI, 2007, v. 4, C. 22, \2, p. 247).

\section{Hegemonia e revolução passiva}

Partindo do pressuposto de que as revoluções foram sempre acompanhadas de processos de restauração, mas também reconhecendo que nenhum desses processos conseguiu eliminar completamente as conquistas revolucionárias, Gramsci (2016, v. 3, C. $13, \int 27$, p. 77) assevera que, “[...] na dialética revolução-restauração, é o elemento ou o elemento restauração que predomina, já que é certo que, no movimento histórico, jamais se volta atrás e não existem restaurações in toto". Sobre a questão, Klebir (2003) acrescenta que a dialética entre revolução e restauração não constitui um jogo mecânico, mas depende substancialmente de fatores subjetivos, a exemplo da consciência histórica dos grupos antagonistas e sua capacidade de determinar e intervir no fluxo concreto daquilo que de fato acontece.

O conceito de revolução passiva ou revolução-restauração formulado por Gramsci afasta-se de uma concepção fatalista da história. Assim, a ideia de que há uma impossibilidade histórica concreta de atingir uma condição pura, sem antagonismos, seria 
um contrassenso. É exatamente em meio a essa contradição que Gramsci contextualiza o conceito de hegemonia a partir de critérios temporais e geopolíticos, em contraposição ao conceito leninista de revolução permanente. ${ }^{4}$

Em oposição à definição de revolução permanente, creditada à Lenin, Gramsci introduz o conceito de hegemonia em um contexto geopolítico, temporal. Depois de 1870, período de expansão europeia, houve um predomínio de novos elementos nas relações sociais, em que se complexificaram as relações de organização e internacionalização dos Estados.

Conceito político da chamada "revolução permanente", surgido antes de 1848 ,
como expressão cientificamente elaborada das experiências jacobinas de 1789 ao
Termidor. A fórmula é própria de um período histórico em que não existiam
ainda os grandes partidos políticos de massa e os grandes sindicatos
econômicos, e a sociedade ainda estava sob muitos aspectos, por assim dizer, no
estado de fluidez: maior atraso do campo e monopólio quase completo da
eficiência político-estatal em poucas cidades [...] (GRAMSCI, 2016, v. 3, C. 13, $\$$
7, p. 24).

O pensador sardo primou por examinar significativos complexos históricos - a exemplo do Renascimento, Reforma e Revoluções Francesas de 1789, 1830 e 1848 - que culminaram em seus estudos sobre o Risorgimento, fascismo e americanismo-fordismo, por entender o potencial revolucionário e restaurador de tais eventos. Sua insistência em tais processos históricos residia em seu propósito de extrair deles linhas gerais de uma teoria da revolução.

Para os Estados que penetraram na fase imperialista, a luta de classes, segundo a ótica gramsciana, havia se convertido na disputa pela hegemonia civil, o que significava a transformação da guerra de movimento em guerra de posição. $O$ desenvolvimento capitalista na sociedade burguesa alcançava, assim, novos contornos que, em sua complexidade, implicavam mudanças nas formas de conflito social. "A revolução permanente, contudo, teria validade ainda para aquelas regiões nas quais a sociedade civil burguesa era ainda embrionária, assim como fora na Revolução Francesa até 1848 e mesmo na Rússia de 1917” (DEL ROIO, 2018, p. 160).

Pode-se aferir, portanto, que a hegemonia burguesa se ergue a partir das revoluções burguesas. Ao analisar os limites da revolução burguesa na Itália, Gramsci identifica sua ocorrência em razão da incapacidade de a classe dirigente captar as amplas massas

\footnotetext{
4 “A Revolução Francesa de 1789-1799 teria oferecido na prática o substrato para a formulação teórica da revolução permanente, até mesmo como concebida por Marx. Essa concepção predominou até os eventos revolucionários de 1848-1849 e foi marcada por uma forma de luta que pode ser identificada como guerra de movimento e como ideologia jacobina. Essa forma de luta e de ideologia só se esgotou definitivamente em 1870-1871, quando da derrota da Comuna de Paris e da unificação de Alemanha e Itália” (DEL ROIO, 2018, p. 159).
} 
populares. Nessa realidade histórica, foram os camponeses a quem Gramsci tratou como classes subalternas, imprescindíveis para formar aliança com a classe operária. $\mathrm{Na}$ Itália, a revolução se deu na forma de uma revolução passiva, ou seja, “[...] como revolução na qual as grandes massas populares não são o sujeito e os protagonistas", e, sim, “[...] são arrastadas pela hegemonia de classes desligadas dos interesses dos estratos populares mais profundos" (GRUPPI, 1978, p. 84).

Destarte, o jacobinismo representou uma reforma intelectual e moral laica, expressão direta das demandas das massas e intelectuais, fundamentada para o desenvolvimento da hegemonia. Nesse ponto, conforme expõe Del Roio (2018), Gramsci questiona as razões que impediram uma revolução burguesa jacobina na Itália, o que impediu o estabelecimento de uma hegemonia jacobina no processo revolucionário italiano, dando lugar a uma hegemonia moderada.

\footnotetext{
Aqui a categoria da hegemonia só pode ser compreendida na medida em que se desdobra e implica outras categorias. A hegemonia jacobina se associa diretamente à revolução permanente e guerra de movimento na construção de uma expressão histórica nacional-popular (DEL ROIO, 2018, p. 160).
}

O conceito de revolução passiva revela a atualidade do pensamento gramsciano na medida em que fornece, ainda hoje, elementos para a interpretação histórica. Não constitui, todavia, uma fórmula. Para Gramsci (2006, v. 1, C. 10, \41, p. 396), não é possível "conceber desenvolvimento histórico como um jogo esportivo, com seu árbitro e suas normas preestabelecidas". Klebir (2003) destaca o rigor metodológico utilizado por Gramsci na elaboração da noção de revolução-restauração, apontando que ele conseguiu não apenas superar conceitos unívocos, mas também desenvolver uma teoria para além do reformismo. Sua metodologia nos obriga, impreterivelmente, a fazer um mergulho na situação histórica concreta.

Gramsci deduz o conceito de revolução passiva a partir de dois princípios marxianos extraídos da obra Contribuição à crítica da economia política:

\footnotetext{
1) nenhuma formação social desaparece enquanto as forças produtivas que nela se desenvolveram ainda encontrarem lugar para um novo movimento progressista; 2) a sociedade não se põe tarefas para cuja solução ainda não tenham germinado as condições necessárias etc. (GRAMSCI, 2002, v. 5, C. 15, § 17, p. 321).
}

A partir da análise do Risorgimento, expressão da revolução passiva na Itália, Gramsci compreende que essa categoria se amplia após a unificação italiana, além de comprovar a instauração de uma hegemonia moderada, cuja ação intelectual, política e moral conseguiu atrair um maior número de aliados e mesmo de adversários. É capaz de, a partir dessa análise, extrair um fundamento teórico da hegemonia, qual seja, 
[...] a supremacia de um grupo social se manifesta em dois modos, como "domínio" e como "direção moral e intelectual". Um grupo social é dominante dos grupos adversários os quais tende a "liquidar" ou a submeter mesmo com a força armada e é dirigente dos grupos afins e aliados (GRAMSCI, 2002, v. 5, C. $19, \rrbracket 24$, p. 62).

E complementa:

[...] não existe uma classe independente de intelectuais, mas cada grupo social tem um grupo intelectual próprio ou tende a formá-lo; porém os intelectuais da classe historicamente (e realisticamente) progressiva, nas condições dadas, exercitam um poder de atração que acaba, em última análise, por subordinar os intelectuais dos outros grupos sociais e assim criar um sistema de solidariedade entre todos os intelectuais com ligações de ordem psicológica (vaidade etc.) e muitas vezes de casta (técnico-jurídicas, corporativas etc.) (GRAMSCI, 2002, v. 5, C. $19, \rrbracket 24$, p. 64$)$.

Del Roio (2018), por sua vez, adverte que a hegemonia somente decorre desse modo enquanto fundada em uma dada materialidade definida no processo produtivo. Expressa-se, pois, na economia e na cultura, mediada pela política, complexo que organiza o conjunto da vida em sociedade.

Ao longo de sua produção, muitos foram os conceitos construídos por Gramsci a partir de seu empenho em compreender os motivos que levaram a classe operária a fracassar na Itália e como essa mesma classe poderia se reorganizar para construir uma nova hegemonia. Nesse período, também procurou desmistificar as distintas expressões da produção científica, filosófica e cultural de seu tempo, apontada em vários momentos. Gramsci, na esteira de Marx, realiza essa tarefa dialogando com as correntes de pensamento que expressavam a representação social de diferentes momentos e avaliando os avanços de tais elaborações teórico-filosóficas e suas reverberações no processo de organização da classe operária.

\section{Hegemonia e americanismo-fordismo}

No Caderno 22, escrito em 1934 e intitulado Americanismo e fordismo, Gramsci desenvolve a ideia de como se construiu a hegemonia da classe dominante nos Estados Unidos da América. Também anuncia os problemas que devem ser investigados no novo modelo de organização da produção que está nascendo na sociedade americana pósPrimeira Guerra Mundial. Pondera que as soluções para tais dificuldades de implementação desse modelo haviam sido pensadas no seio da sociedade capitalista pela classe dominante - burguesia -, o que implicaria uma série de consequências para a classe dominada - o proletariado. 
De acordo com Gramsci (2007, v. 4, C. 22, \11, p. 266), o americanismo-fordismo tratava-se do "[...] maior esforço coletivo até agora realizado para criar, com rapidez inaudita e com uma consciência do objetivo, jamais vista na história, um tipo novo de trabalhador e de homem [...]". Semeraro (2015) acrescenta que Gramsci entendia americanismo e fordismo como indissociáveis, uma vez que, atrelado aos modernos artefatos, havia um projeto orgânico de sociabilidade direcionado a sintonizar as necessidades de industrialização ao modo de vida das pessoas, garantindo a hegemonia da classe dominante.

Arriscamo-nos a dizer que a redação do Caderno 22 ocorreu de forma semelhante à do Caderno 19, que trata da unificação na Itália: pela necessidade de compreender a história dos grupos sociais subalternos. Essa concepção se expressa majoritariamente no Caderno 25. Para o revolucionário sardo, o americanismo e fordismo surgem da exigência do desenvolvimento das forças produtivas posta pela sociedade burguesa, evidenciando assim "[...] a passagem do velho individualismo econômico para a economia programática [...]" (GRAMSCI, 2007, v. 4, C. 22, \1, p. 241), com o objetivo de revitalizar a sociedade vigente.

Gramsci (2007) elenca os problemas essenciais a serem investigados no Caderno 22: 1) a criação de um novo mecanismo de acumulação e distribuição do capital financeiro, que tenha como base imediata a produção industrial, a fim de substituir a camada que estava no poder; 2) a questão sexual; 3) identificar se o americanismo se constitui como uma revolução passiva ou do tipo jacobina; 4) a questão da racionalização da composição demográfica europeia; 5) averiguar se seu desenvolvimento deve ter seu ponto de partida na produção ou na esfera jurídica; 6) a questão dos altos salários; 7) o fordismo como uma alternativa de superação da lei tendencial da queda da taxa de lucro; 8) o efeito na subjetividade dos trabalhadores causados pela coerção mecânica; 9) investigar o Rotary Clube e a Maçonaria como instituições da sociedade civil surgidas como necessidade de construir a hegemonia do americanismo e fordismo; entre outros. Essa é uma nota do tipo B, de redação única, provavelmente Gramsci a escreveu quando foi passar a limpo outro caderno que se transformou no Caderno 22.

Havia a absoluta clareza de que a atividade revolucionária dependia diretamente da emancipação do subalterno, enriquecido de cultura geral, com capacidade para deliberar sobre os problemas sociais existentes e, sobretudo, convencido do projeto de sociedade a ser alcançado. Diante dessa necessidade, considerava imprescindível uma ampla reforma moral e intelectual. Ao estudar o americanismo, Gramsci tencionava compreender aquela revolução que ocorrera de forma passiva de modo a apreender uma maneira possível de 
transportá-la para uma transição socialista, um americanismo de marca não americana, uma classe disciplinada e consciente dos objetivos do trabalho social fundamental para suprir as necessidades humanas, gerando cada vez mais liberdade.

O que hoje é chamado de "americanismo" é em grande parte a crítica
antecipada feita pelas velhas camadas que serão esmagadas pela possível nova
ordem e que já são vítimas de uma onda de pânico social, de dissolução, de
desespero; é uma tentativa de reação inconsciente de quem é impotente para
reconstruir e toma como ponto de apoio os aspectos negativos da
transformação. Não é dos grupos sociais "condenados" pela nova ordem que se
pode esperar reconstrução, mas sim daqueles que estão criando, por imposição
através do próprio sofrimento, as bases materiais desta nova ordem estes
últimos "devem" encontrar o sistema de vida "original" e não marca americana,
a fim de transformarem em "liberdade" o que hoje é necessidade" (GRAMSCI,
2007, v. 4, C. $22, \mathbb{1 5}$ p. p. 280).

A seguir, uma célebre citação gramsciana acerca de seu conceito de hegemonia. No entanto, chama-se atenção para o fato de que não pode ser tomada como regra, ou como lei presente na teoria do capital, mas como uma constatação a partir da análise de uma conjuntura, de uma situação concreta, numa sociedade concreta: a americana. No dizer do revolucionário sardo, a partir da existência de condições objetivas preliminares, foi

[...] relativamente fácil racionalizar a produção e o trabalho, combinando habilmente a força (destruição do sindicato operário de base territorial) com a persuasão (altos salários, diversos benefícios sociais, habilíssima propaganda ideológica e política) e conseguindo centrar toda a vida do país na produção. A hegemonia nasce da fábrica e necessita, apenas, para ser exercida, de uma quantidade mínima de intermediários profissionais da política e da ideologia (GRAMSCI, 2007, v. 4, C. 22, \2, p. 247-248).

A categoria hegemonia aqui é utilizada por Gramsci para compreender o processo de implementação do americanismo-fordismo como revolução passiva, revoluçãorestauração, com o objetivo de reformar o capitalismo, alcançar novos patamares de desenvolvimento das forças produtivas e, consequentemente, uma maior exploração da força de trabalho. A construção de um novo modelo de organização das forças produtivas e dos modos de vida na América necessitou unir consenso e direção, assim como construir alianças com grupos favoráveis a essas forças sociais. O marxista complementa ainda que, por se tratar de uma sociedade racionalizada, a “[...] 'estrutura' domina mais imediatamente as superestruturas e estas são 'racionalizadas' (simplificadas e reduzidas em número)" (GRAMSCI, 2007, v. 4, C. 22, \$2, p. 248).

Até a crise de 1929, nascedouro de uma superestrutura, Gramsci (2007, v. 4, C. 22, \2, p. 248) entendia ainda não ter sido posta “[...] a questão fundamental da hegemonia [...]", entendida por ele como a formação de um novo homem. Del Roio (2018) arremata esclarecendo que o taylorismo, concebido no seio do mais avançado Estado capitalista, os EUA, deveria ser adequado à transição socialista, e sua função de exploração do trabalho 
precisaria se colocar a serviço do surgimento de uma classe operária disciplinada e consciente dos objetivos do trabalho social.

Em meio à análise do americanismo-fordismo, Gramsci menciona três instituições: Maçonaria, Igreja Católica e Rotary Club. ${ }^{5}$ Sobre esta última, observa que buscava ser uma instituição laica, porém sua função como aparelho privado de hegemonia era "a difusão de um novo espírito capitalista" (GRAMSCI, 2007, v. 4, C. 5, \2, p. 295). Abre-se, aqui, um parêntese para evidenciar uma semelhança entre a noção gramsciana de hegemonia e a divisão ocorrida, proporcionalmente, no interior do Rotary Club: uma organicidade baseada, inicialmente, na gênese de uma opinião consensual interna à elite; depois, há uma propagação dessa concepção, buscando um consenso mais amplo na sociedade.

Entretanto, um estágio mais avançado de hegemonia pressupõe o consentimento dos dominados, logo, a anuência de uma visão de mundo, antes externa, que se incorpora. A atenção dada pelo Rotary à vida moral e à formação de pequenas comunidades em meio à cidade grande constitui, pois, um ponto crucial, tendo em vista ser uma intuição formada por elites de ancestralidade europeia, afinada a credos religiosos e que reclama mudança no modo de vida a partir da experiência de vida de seus fundadores.

A respeito da formação do ser social, Gramsci situa-o historicamente a partir de suas condições materiais de existência, tomando como opostos a ação real promovida pelo americanismo e o espírito de gladiador:

[...] está criando um futuro que é intrínseco à sua atividade objetiva e sobre o qual se prefere não falar. $O$ segundo cria apenas fantoches aperfeiçoados, recortados segundo um figurino retoricamente prefixado, e que se reduzirão a pó quando forem cortados os fios externos que the dão a aparência de movimento e de vida (GRAMSCI, 2007, v. 4, C. 22, \5, p. 254).

Gramsci $(2007$, v. 4, C. 22 , \11, p. 266) compreendia o americanismo-fordismo como uma fase que "[...] será superada através da criação de um novo nexo psicofísico de um tipo diferente dos anteriores e, certamente, de um tipo superior". Embora o revolucionário sardo critique a violenta mecanização a que a classe burguesa submeteu os operários, inclusive controlando suas vidas privadas, ele entende que há avanços conquistados naquela nova forma de organizar o trabalho, em virtude do aumento da produtividade, contudo reivindica que “[...] o conjunto de trabalhadores da fábrica deva ser concebido como um 'trabalhador coletivo' - eis os pressupostos do movimento de fábrica

\footnotetext{
${ }^{5}$ Associação de homens de negócios fundada pelo americano Paul P. Harris, em 1905. Tem por base uma ideologia filantropista, atingindo dimensão internacional em 1912. Tal instituição foi analisada por Gramsci ao examinar "as relações econômicas e políticas reais que encontram sua forma de organização, sua articulação e sua funcionalidade $[. .$.$] na vida estatal [. .$.$] , na vida interestatal [. .$.$] e na vida das associações políticas e culturais$ [...], sindicais [e] econômicas" (GRAMSCI, 2016, v. 3, \36, p. 91).
} 
que tende a fazer com que se torne 'subjetivo' o que está dado 'objetivamente”' (2007, v. 4, C. $9, \int 67$, p. 313).

Conclui sua análise acerca do americanismo e fordismo, sustentando o protagonismo das classes subalternas para a superação da sociedade capitalista, uma vez que:

[...] Não é dos grupos sociais "condenados" pela nova ordem que se pode esperar a reconstrução, mas sim daqueles que estão criando, por imposição e através do próprio sofrimento, as bases materiais desta nova ordem: estes últimos "devem" encontrar o sistema de vida "original", e não de marca americana, a fim de transformar em "liberdade" o que hoje é "necessidade" (GRAMSCI, 2007, v. 4, C. 22, \$15, p. 280).

Depois de toda essa análise, Gramsci apresenta uma questão central: se esse novo modelo de organização da produção teria capacidade de se generalizar para o restante do mundo, criando um novo tipo de operário mundial, ou seria uma especificidade de uma experiência nascida e findada na sociedade americana, visto que tal coerção aniquilaria a força de trabalho. O próprio revolucionário sardo responde a esse questionamento ao afirmar a racionalidade do fordismo e, a partir dela, a possibilidade de generalizar-se. Assinala que haveria de combinar consenso e coerção, conquistados também por meio de altos salários, uma vez que formar um corpo tecnicamente qualificado para a produção nunca foi tarefa fácil. Se olharmos para a História, o fordismo não só se expandiu mundialmente, conforme a previsão gramsciana, como também estabeleceu, pelo menos nos países mais desenvolvidos, diferentes tipos de Estados de Bem-Estar Social.

$\mathrm{Na}$ teoria gramsciana, todo novo modo de vida é construído, inicialmente, a partir da luta contra a velha ordem, por meio de coerção mecânica. Contudo, até o momento atual, as transformações nos modos de vida ocorreram de forma extremamente violenta, já que sempre se deram sob o domínio de uma classe em detrimento de outras. Embora Gramsci reconheça a necessidade de coerção, reivindica "uma coerção de novo tipo", que somente pode ser pensada como autocoerção e autodisciplina "exercida pela elite de uma classe sobre a própria classe” (GRAMSCI, 2007, v. 4, C. 22, \ 10, p. 265). Chega a criticar Trotsky, a quem chama Leão Davidovi em alusão à sua defesa de implantar trabalho obrigatório com métodos de militarização, em 1920, durante o Congresso Pan Russo dos sindicatos (GRAMSCI, 2007, v. 4, C. 22, \10, p. 372).

Gramsci $\left(2007\right.$, v. 4, C. 22 , $\int 2$, p. 248) chama atenção para o fato de que o novo modelo de organização da produção exige um novo tipo de trabalhador “[...] um novo tipo humano, adequado ao novo tipo de trabalhador e de processo produtivo [...]". Interessante 
observar que ele não reduz o ser humano ao trabalho, ao evidenciar a formação de um novo homem que se adapte às novas formas de trabalho.

\section{Considerações Finais}

Gramsci nos ensina que uma classe se torna dominante de duas maneiras: dirigindo as classes aliadas e dominando as classes adversárias, mesmo que pela força armada. Entretanto, tal classe que aspira chegar ao poder pode e deve se tornar dirigente, mesmo antes de se fazer Estado, o que significa conquistar uma base social para um projeto de sociedade baseada na igualdade: o comunismo. Ao utilizar o exemplo do americanismofordismo, demonstra que a hegemonia nasce na racionalização criada no processo de trabalho e, impondo sua visão de mundo, obtém o consenso das classes subalternas. Diferentemente do Risorgimento que, ao cindir domínio e direção, investindo mais no primeiro, precisou do fascismo para conseguir a disciplina dos trabalhadores. Enquanto no primeiro modelo a disciplina se dá por uma coerção mediante o consenso, na segunda ocorre pela força.

O revolucionário sardo vislumbrava no devir histórico a possibilidade de construção de uma nova ordem social, pautada pelo trabalho livremente associado, em que os grupos sociais subalternos conseguissem, por meio de seu trabalho, libertar o homem de suas necessidades, num processo cada vez mais avançado da técnica aplicada. Para ele, era imprescindível ter um operariado dotado dos mais avançados conhecimentos, e que toda essa capacidade técnica e científica estivesse vinculada aos interesses políticos dos subalternos.

A constituição de uma nova hegemonia requer tanto a transformação radical das relações sociais de produção quanto a edificação de uma nova concepção de mundo que ganhe as massas. E, para que se recriem novas maneiras de produzir nossa sobrevivência, há a necessidade de uma educação em sentido estrito que esteja organizada com base no trabalho como transformação da natureza. A formação de um corpo de homens com alta qualificação técnico-científica é fundamental para a implementação dessa nova forma de sociabilidade.

Dada a brevidade desta comunicação e, portanto, sua incapacidade de esgotar a temática, reafirmamos a necessidade de mais estudos que aprofundem as características do atual momento de desenvolvimento do capitalismo, bem como as características peculiares de cada Estado nacional, a fim de apreender qual deve ser o ponto de partida para o processo de construção da hegemonia da classe trabalhadora em cada país, condição imprescindível apara a emancipação dos subalternos. 


\section{Referências}

DEL ROIO, Marcos. Gramsci e a emancipação do subalterno. São Paulo: Editora Unesp, 2018.

DEL ROIO, Marcos. Os prismas de Gramsci: a formulação da frente única (1919-1926). São Paulo: Boitempo, 2019.

DIAS, Edmundo Fernandes. Hegemonia: Nova Civiltà ou domínio ideológico? História e Perspectivas, Uberlândia, p. 5-43, 1991.

GRAMSCI, Antonio. Cadernos do cárcere. Edição e Tradução de Carlos Nelson Coutinho. Rio de Janeiro: Civilização Brasileira, 2002. v. 5.

GRAMSCI, Antonio. Escritos políticos. Organização e tradução de Carlos Nelson Coutinho. Rio de Janeiro: Civilização Brasileira, 2004. v. 2.

GRAMSCI, Antonio. Cadernos do cárcere. Edição e tradução de Carlos Nelson Coutinho. Rio de Janeiro: Civilização Brasileira, 2006. v. 1.

GRAMSCI, Antonio. Cadernos do cárcere. Edição e tradução de Carlos Nelson Coutinho. Rio de Janeiro: Civilização Brasileira, 2007. v. 4.

GRAMSCI, Antonio. Cadernos do cárcere. Edição e tradução de Carlos Nelson Coutinho. Rio de Janeiro: Civilização Brasileira, 2016. v. 3.

GRUPPI, Luciano. O conceito de hegemonia em Gramsci. Tradução de Carlos Nelson Coutinho. Rio de Janeiro: Graal, 1978.

KLEBIR, Sabine. "Revolução-restauração" e "revolução passiva": conceitos de história universal. In: COUTINHO, Carlos Nelson; TEIXEIRA, Andréa de Paula (org.). Ler Gramsci, entender a realidade. Rio de Janeiro: Civilização Brasileira, 2003.

PORTELLI, H. Gramsci e o bloco histórico. Rio de Janeiro: Paz e Terra, 1977.

SEMERARO, Giovanni. A concepção de trabalho em Gramsci: constituição ontológica e princípio educativo. Trabalho \& Educação, Belo Horizonte, v. 24, n. 1, p. 233-244, 2015. 